\section{Relativa restritiva em perspectiva construcional}

\author{
Restrictive relative on a \\ constructional approach
}

Edvaldo Balduíno BISPO (UFRN) edbbispo@gmail.com

Recebido em: 12 de mar de 2018. Aceito em: 24 de maio de 2018.

\section{.}

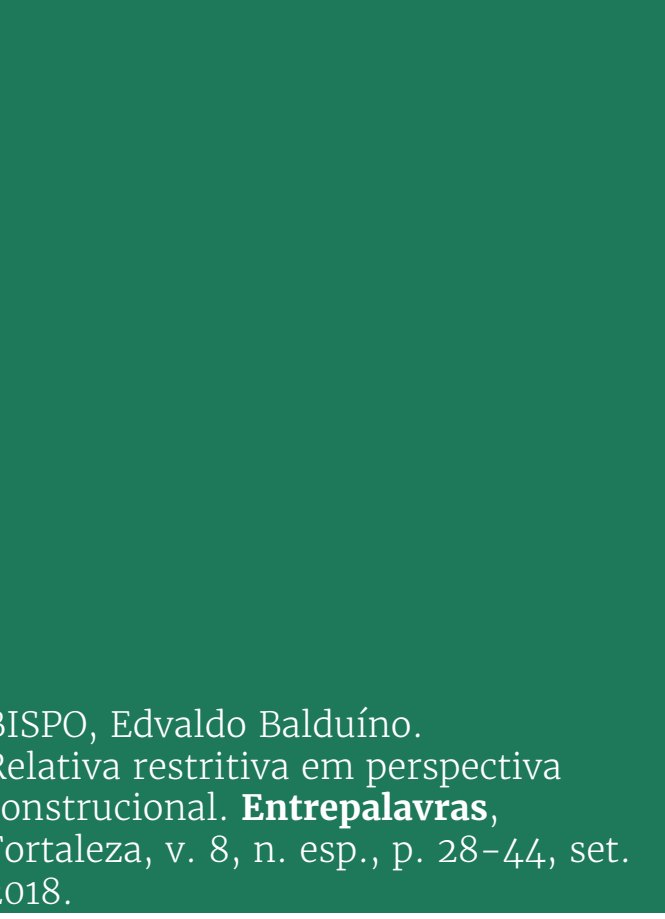

BISPO, Edvaldo Balduíno.

Relativa restritiva em perspectiva

construcional. Entrepalavras,

Fortaleza, v. 8, n. esp., p. 28-44, set.

Resumo: Este trabalho investiga a oração relativa restritiva finita em perspectiva construcional. Objetiva caracterizar, em termos formais e funcionais, esse tipo oracional, tomando-o como uma construção e propor uma organização hierárquica para seus padrões microconstrucionais. Sustenta-se teórico-metodologicamente na Linguística Funcional Centrada no Uso (FURTADO DA CUNHA; BISPO, 2013) e em contribuições da Gramática de Construções (GOLDBERG, 2006; TRAUGOTT; TROUSDALE, 2013). Trata-se de uma pesquisa quali-quantitativa cujos dados empíricos provêm dos corpora Projeto História do Português Brasileiro e Discurso \& Gramática. Os resultados revelam que a construção relativa restritiva finita sanciona três padrões microconstrucionais distintos aos quais estão relacionados fatores cognitivos, a exemplo de economia de esforço, e aspectos interacionais, como demandas por maior clareza, expressividade e usos mais ou menos monitorados da língua.

Palavras-chave: Relativa restritiva. Linguística Funcional Centrada no Uso. Gramática de Construções. 
Abstract: This paper focuses on the finite restrictive relative clause in a constructional approach. It aims to characterize this kind of clause formally and functionally, by taking it as a construction and proposing a hierarchical organization for its microconstructional patterns. This study is theoretically and methodologically supported by Usage-based Functional Linguistics (FURTADO DA CUNHA; BISPO, 2013) and by contributions from the Constructions Grammar (GOLDBERG, 2006; TRAUGOTT; TROUSDALE, 2013). It is both qualitative and quantitative research whose data come from the corpora Projeto História do Português Brasileiro and Discurso \& Gramática. The results show that the finite restrictive relative construction sanctions three distinct microconstructional patterns to which cognitive factors are related, such as effort economy, and interactional aspects, such as demands for greater clarity, expressiveness and more or less formal uses of language.

Keywords: Restrictive relative. Usage-based Functional Linguistics. Construction Grammar.

\section{Introdução}

Diferentes estudos empreendidos acerca das orações relativas indicam o quão amplo é o leque de possibilidades de abordagem do fenômeno e como essas orações constituem campo fértil de investigação. Elas têm sido tratadas sob distintos vieses teóricos (formalista, variacionista, funcionalista) e sob aspectos variados (estratégias de relativização, formas alternativas de organização da relativa, aposição vs restrição, diacronia e sincronia, entre outros).

Nessa direção, estudos pioneiros, a exemplo de Mollica (1977) e Tarallo (1983), dão conta das estratégias de relativização; outros discutem a variação no uso das relativas, como é o caso de Correa (1998), Pinheiro (1998) e Varejão (2006); outros mais se dedicam a descrever e a analisar formalmente esse tipo oracional, conforme se dá em Brito (1988), Kenedy (2007), Marchesan (2012); alguns se voltam a aspectos funcionais no uso dessas orações, segundo encontramos em Souza (2009), Bispo (2009, 2014a) e Decat (2011); há também pesquisas que contemplam descrição formal-funcional e questões atinentes ao ensino das relativas, de que são exemplos Bispo (2007), Leitão (2009), Amorim (2011), Câmara (2015); estudos contemplam ainda o viés diacrônico, como os de Tarallo (1983), Bispo (2014b), Silva (2011). Por essa pequena lista, é possível observar que as abordagens a esse fenômeno linguístico são diversas.

Neste artigo, focalizo, de modo particular, a relativa restritiva finita (desenvolvida) sob o enquadre teórico da Linguística Funcional Centrada no Uso (doravante, LFCU), tomando-a como uma construção (pareamento forma-função) na linha de Goldberg (2006), Croft (2001) e Traugott e Trousdale (2013). Nesse sentido, o tratamento dado envolve um olhar construcionista sobre a oração relativa. 
v. 8 (esp.)

$28-44$ set. 2018

Três objetivos orientam este empreendimento: i) caracterizar a relativa restritiva finita em termos formais e funcionais; ii) identificar padrões estruturais que licenciam as ocorrências desse tipo oracional; iii) organizar, hierarquicamente, esses padrões, relacionando-os ao esquema maior que os sanciona. Assumo a hipótese geral de que as instâncias de uso dessa oração revelam padrões microconstrucionais específicos aos quais se associam questões de ordem cognitiva e interacional. O material empírico utilizado provém de dois bancos de dados: corpus do Projeto História do Português Brasileiro ${ }^{1}$ (PHPB) e corpus Discurso \& Gramática - a língua falada e escrita na cidade do Rio de Janeiro (VOTRE; OLIVEIRA, 1995). Também foram utilizados dados oriundos de sites e de revistas de grande circulação.

O artigo está assim estruturado: na seção 1, caracterizo o aporte teórico que sustenta as discussões; na seção seguinte, trato de aspectos metodológicos da pesquisa; na terceira seção, identifico padrões estruturais da relativa restritiva finita com base no levantamento de dados e apresento uma organização hierárquica desses padrões; a quarta seção é dedicada à discussão de aspectos funcionais da construção em tela; por último, faço as considerações finais.

\section{Abordagem Funcional Centrada no Uso}

Cunhado no âmbito do Grupo de Estudos Discurso \& Gramática (D\&G), o termo Linguística Funcional Centrada no Uso (LFCU) designa uma tendência de estudos de natureza funcional-cognitivista, pois conjuga pressupostos do funcionalismo linguístico norte-americano e da Linguística Cognitiva. Representa desdobramento do que Martelotta (2011) denominou Linguística Centrada no Uso em correspondência a Usage-based linguistics (BYBEE, 2010), o que equivale, em geral, a Cognitive-Functional approach (TOMASELLO, 1998).

Conforme essa abordagem, os usos linguísticos resultam de modelos convencionalizados com base na interface linguagem, cognição e ambiente sócio-histórico. A inter-relação dessas três dimensões motiva a fixação de padrões gramaticais, via ritualização, a partir de ambientes interacionais específicos (MARTELOTTA, 2011; FURTADO DA CUNHA; BISPO, 2013).

Um dos postulados básicos da LFCU, conforme destacam Furtado da Cunha, Bispo e Silva (2013), é o fato de que a estrutura da

\footnotetext{
${ }^{1}$ https://sites.google.com/site/corporaphpb/.
} 
língua emerge à medida em que é usada (BARLOW; KEMMER, 2000; BYBEE, 2010). Desse modo, a teoria busca descrever e explicar os fatos linguísticos com base nas funções (semântico-cognitivas e discursivopragmáticas) que desempenham nos diversos contextos de uso da língua, integrando sincronia e diacronia (BYBEE, 2010).

As funções da língua têm papel fundamental na descrição de suas formas, de modo que cada entidade linguística se define em relação ao papel que desempenha nos processos reais de comunicação (FURTADO DA CUNHA; BISPO, 2013). Por isso, segundo esses autores, a LFCU procura trabalhar com dados reais de fala e/ou de escrita, inseridos em contextos efetivos de comunicação, evitando lidar com frases criadas.

Para essa perspectiva teórica, as categorias linguísticas se comportam de modo semelhante a categorias conceituais humanas (FURTADO DA CUNHA; BISPO, 2013). Assim, conforme os autores, as estruturas linguísticas são concebidas como esquemas cognitivos do mesmo tipo que encontramos em outras habilidades não linguísticas, ou seja, como procedimentos relativamente automatizados que se utilizam para realizar coisas comunicativamente. Destaca-se que é a frequência de uso de determinada construção que leva a seu estabelecimento no repertório do falante e faz dela uma unidade de processamento.

Nesse contexto teórico, a linguagem é compreendida como "um complexo mosaico de atividades comunicativas, cognitivas e sociais estreitamente integrado a outros aspectos da psicologia humana" (TOMASELLO, 1998, p. ix). A língua, como parte desse mosaico, é vista como um código parcialmente arbitrário, dada sua adaptabilidade às necessidades interacionais, sociais e cognitivas dos usos que dela fazemos. Nos dizeres de Bybee (2010), consiste em um "sistema adaptativo complexo". Dito de outro modo, a língua é um "objeto maleável", uma vez que se sujeita às pressões do uso, salientando também a atuação de processos cognitivos de domínio geral na codificação linguística. Deriva dessa abordagem funcionalista uma concepção de gramática como conjunto de padrões linguísticos regulares aberto, fortemente suscetível e intensamente afetado pelo uso (MARTELOTTA, 2011).

Estudos embasados na LFCU têm utilizado muito frequentemente formulações da Gramática de Construções (GC), a qual representa uma vertente de estudos em Linguística Cognitiva. Para a GC, a unidade básica da língua é a construção. Por construção, compreende-se o pareamento simbólico e convencionalizado de forma-função. Goldberg (2006, p. 5) salienta: "Qualquer padrão linguístico pode ser reconhecido como 
v. 8 (esp.)

$28-44$ set. 2018

uma construção", ou seja, desde morfemas até a organização textual, passando por padrões de estrutura argumental, desde que haja um conteúdo semântico-pragmático a ele associado.

O principal postulado da GC é que as línguas são, na verdade, complexas e dinâmicas redes de construções, pois estas são a unidade básica da gramática de qualquer sistema linguístico. As diversas construções de uma língua diferenciam-se somente em termos de especificação, tamanho e conceito. Croft (2001) estabelece que, em uma construção, estão associadas duas dimensões: a da forma e a do significado (função), estando as duas interligadas por elo de correspondência simbólica. O autor atribui ao polo da forma as propriedades fonológicas, morfológicas e sintáticas e ao polo da função as propriedades semânticas, discursivas e pragmáticas.

A construção é caracterizada por um conjunto de três propriedades, a saber: esquematicidade, composicionalidade e produtividade. Tratase de propriedades que se definem pela gradiência, o que nos leva a admitir a existência de construções menos ou mais esquemáticas, menos ou mais composicionais, menos ou mais produtivas (GOLDBERG, 1995; TRAUGOTT; TROUSDALE, 2013). Dessas propriedades, interessam, para este estudo, a esquematicidade e a produtividade.

A esquematicidade diz respeito ao fato de a construção servir como um modelo abstrato/ virtual que captura a generalidade de padrões de uso. Sob essa perspectiva, as construções podem ser totalmente abertas (não especificadas), como o esquema oracional transitivo SVO, sem especificação dos elementos que a preenchem; parcialmente especificadas, como se pode ver na sequência dar $\mathrm{SN}$, em que um dos elementos já é definido; totalmente especificadas (ou idiossincráticas), tal como a expressão tirar o cavalo da chuva, em que todos os elementos já são determinados.

Já a produtividade, conforme Traugott e Trousdale (2013), relaciona-se ao grau em que uma construção mais esquemática sanciona outras menos esquemáticas (subesquemas ou microconstruções), ou seja, tem a ver com a extensibilidade de uma construção. É o que se dá, por exemplo, com o esquema SUJ + PRED, que pode sancionar diferentes estruturas menos esquemáticas, como a construção intransitiva (S V) ou a transitiva (S V O) ou a ditransitiva (S V OD OI).

Essas duas propriedades estão relacionadas entre si, no sentido de que, quanto mais esquemática for uma construção, mais potencialmente produtiva ela será, no sentido de poder sancionar mais types ou microconstruções. 


\section{Aspectos metodológicos}

Metodologicamente, a pesquisa empreendida é qualiquantitativa, pois, ao mesmo em que busca explicitar a associação formafunção da relativa restritiva finita, identificando fatores cognitivos e interacionais implicados em suas instâncias de uso, descreve padrões estruturais dessa construção com base na frequência de uso, aferida quantitativamente.

A fonte dos dados para esta investigação são textos provenientes, em sua maioria, do corpus do Projeto História do Português Brasileiro (PHPB), seção Minas Gerais, especialmente cartas particulares escritas nos séculos XVIII, XIX e XX, e do corpus Discurso \& Gramática (D\&G), seção Rio de Janeiro, particularmente textos falados e escritos produzidos por informantes do ensino superior. Cabe assinalar que os textos que compõem o D\&G foram produzidos no fim do século XX e organizam-se em cinco configurações prototípicas: narrativa de experiência pessoal, narrativa recontada, descrição de local, relato de procedimento e relato de opinião. Também são utilizadas amostras retiradas de sites da internet e de revistas de circulação nacional.

Para aferição da frequência de uso dos padrões estruturais identificados nas ocorrências da relativa restritiva, foi controlado, quantitativamente, o conjunto de dados oriundos das cartas particulares do PHPB e dos textos do $D \& G$. Os das demais fontes não foram assim controlados por não haver necessidade, já que serviram ao propósito de atestar a atuação de aspectos cognitivos e sociointeracionais nos usos do tipo oracional em tela.

As instâncias de uso identificadas foram tabuladas conforme semelhança formal e funcional para definição dos padrões microestruturais da relativa restritiva e para sua posterior caracterização em termos de esquematicidade e produtividade. O estabelecimento desses padrões permitiu a proposição de uma organização hierárquica em rede. A tabulação dos dados considerou ainda, no caso do corpus $D \& G$, as modalidades da língua, falada e escrita, no sentido de verificar possível influência desse aspecto no uso dos padrões identificados.

As amostras flagradas no material empírico utilizado também proporcionaram a observação de propriedades funcionais de cada padrão microestrutural definido. 
v. 8 (esp.) $28-44$ set. 2018

\section{Padrões microestruturais da relativa restritiva finita}

Com base na observação das ocorrências da relativa restritiva e no levantamento de dados a que procedi, pude identificar formas distintas de realização desse tipo oracional, conforme já o fizeram outros pesquisadores. As amostras de (1) a (4) ilustram possibilidades.

(1) A situação em que o país se encontra é vergonhosa. Corrupção por todos lados, criação de impostos absurdos... enfim, é uma baderna geral. (D\&G Rio de Janeiro, língua escrita)

(2) Ele pegou o carro e começou a descer a Conde de Bonfim na Tijuca ao chegar na rua que ele ia comprar a cerveja ele reduziu a velocidade ligou a seta e dobrou cruzando a pista da esquerda. (D\&G Rio de Janeiro, língua escrita)

(3) a Thelma tentando levar o carro para o acostamento, finalmente conseguimos parar, descemos do carro e com um certo desespero que as duas fingiam não ter, começamos a "operação" troca de pneus. (D\&G Rio de Janeiro, língua falada)

(4) eu vou contar uma história triste... eh::... o:: meu marido tem um amigo... que::... ele era:: esportista... acho que ele era nadador... profissional... e ele/ apareceu um:.... um... negócio nas costas dele ( $D \& G$ Rio de Janeiro, língua falada)

A oração destacada em (1), que exemplifica a estratégia canônica de relativização introduzida por preposição, apresenta a configuração PREP REL S V. Em (2), temos um caso de relativa cortadora, com a ausência da preposição em, correspondendo à estrutura REL S V OD. Já a oração marcada em (3), exemplo de uma relativa canônica sem preposição, tem a forma REL S V. Por fim, a oração negritada em (4), que ilustra uma copiadora, tem como sujeito um pronome cópia correferente ao antecedente da relativa, exibindo a configuração REL $\mathrm{S}_{\mathrm{P} \text { RONi }}$ V PRED.

Os arranjos sintagmáticos internos à oração relativa podem variar conforme a presença ou não de determinados termos (complementos e adjuntos, por exemplo) e segundo sua ordenação na cláusula. Portanto, as configurações sintáticas instanciadas pelas ocorrências da relativa restritiva verificadas na amostra utilizada podem ser representadas pelas seguintes microestruturas esquemáticas: PREP REL V (X), REL V $(\mathrm{X})$ e $\mathrm{REL}_{\mathrm{i}} \mathrm{PRON}_{\mathrm{i}}^{2} \mathrm{~V}(\mathrm{X})$, em que (X) representa elemento opcional e com posição variável na cláusula.

${ }^{2}$ Este elemento pode preceder ou suceder o verbo e atuar como sujeito ou complemento verbal. O índice ${ }_{(\mathrm{i})}$ denota que há correferência. 
O primeiro padrão responde pelas instâncias da relativa canônica com preposição; o segundo sanciona tanto as canônicas sem preposição quanto as cortadoras; o último deles licencia as chamadas copiadoras.

O levantamento de dados mostrou maior frequência da microestrutura REL V (X) tanto no corpus do PHPB quanto no D\&G. As tabelas 1 e 2 reúnem os quantitativos desses corpora.

Tabela 1 - Distribuição das ocorrências no PHPB por microestrutura e sincronia

\begin{tabular}{ccccccc}
\hline Padrão estrutural & \multicolumn{2}{c}{ Século XVIII } & \multicolumn{2}{c}{ Século XIX } & \multicolumn{2}{c}{ Século XX } \\
\hline REL V $(X)$ & 285 & $81,7 \%$ & 139 & $86,9 \%$ & 86 & $94,6 \%$ \\
\hline PREP REL V $(X)$ & 60 & $17,2 \%$ & 19 & $11,9 \%$ & 4 & $5,4 \%$ \\
\hline REL $_{\mathrm{i}}$ PRON $_{\mathrm{i}}$ V $(\mathrm{X})$ & 4 & $1,1 \%$ & 2 & $1,2 \%$ & - & - \\
\hline TOTAL & 349 & $100 \%$ & 160 & $100 \%$ & 90 & $100 \%$ \\
\hline Fonte: Corpus PHPB. & & & & & &
\end{tabular}

Tabela 2 - Distribuição das ocorrências no D\&G por microestrutura e modalidade

\begin{tabular}{ccccccc}
\hline Padrão estrutural & \multicolumn{2}{c}{ Fala } & \multicolumn{2}{c}{ Escrita } & \multicolumn{2}{c}{ Total } \\
\hline REL V $(\mathrm{X})$ & 103 & $95,4 \%$ & 47 & $75,8 \%$ & 150 & $88,2 \%$ \\
\hline PREP REL V $(\mathrm{X})$ & 2 & $1,8 \%$ & 15 & $24,2 \%$ & 17 & $10,0 \%$ \\
\hline REL $_{\mathrm{i}}$ PRON $_{\mathrm{i}}$ V $(\mathrm{X})$ & 3 & $2,8 \%$ & - & - & 2 & $1,8 \%$ \\
\hline TOTAL & 107 & $100 \%$ & 62 & $100 \%$ & 170 & $100 \%$ \\
\hline Fonte: Corpus D\&G Rio de Janeiro. & & & & &
\end{tabular}

Fonte: Corpus D\&G Rio de Janeiro.

Conforme mostram os quantitativos das duas tabelas, o padrão mais frequente foi o REL V (X) e o menos recorrente, $R_{L} L_{i} P R O N_{i} V(X)$. Essa realidade se deve ao fato de que, no primeiro caso, o padrão licencia as relativas de sujeito e objeto direto - funções mais comumente relativizadas - e as não canônicas de funções preposicionadas. Já o outro padrão sanciona uma estratégia sujeita à avaliação social negativa, a copiadora (cf. BISPO, 2014b), daí ser mais evitada. Vejamos estas amostras:

(5) Certa vez fui à Petrópolis com uma amiga que precisava resolver alguns problemas. Fomos de carro e ela que dirigia há pouco tempo, nunca tinha dirigido na Serra de Petrópolis. (D\&G Rio de Janeiro, língua escrita)

(6) Snr ${ }^{a}$ D. Clara Felicia da Roza Minha Snr. ${ }^{a}$ com fiquei devendo hus pouco de mil reis deque he meu fiador Sr. ${ }^{\circ}$ Jose Teixr. $^{a}$ da Costa ê este q quero dar sem de mora epara este jeito nesseçito do favor vm. ${ }^{\text {ce }}$ correrme com a conta que vm. ${ }^{\text {ce }}$ mehe devedora ou todos ou algua parte; que ate miado [...] (PHPB, carta particular, século XVIII) 
v. 8 (esp.) $28-44$ set. 2018

(7) como é que a minha sala? ((riso)) (ué)... tem dois... dois ambientes... né? uma tem a... mesa de jantar:.... a outra tem a televisão... o sofá... a mesa... isso? mais? eh:.... tem dois sofás grandes de três lugares... duas poltronas... uma mesinha de canto... uma mesa de centro... um aparelho de som já no outro lado... com a... com a mesa de jantar... uma varandinha... onde tem as minhas plantas que eu gosto... o que mais? tem um.. (D\&G Rio de Janeiro, língua falada)

(8) descrever... eu estava pensando nisso... não/ sabe que eu não tenho... o meu quarto não é aquele... lugar que eu gosto de ficar... deveria ser... né? todo mundo é... fala que o quarto é o melhor lugar... que se acha... teu... né? e tal... mas... não sei... eu não... eu não sinto muito assim:.... (D\&G Rio de Janeiro, língua falada)

Observemos que, nesses dados, temos orações com o elemento relativizado em diferentes funções sintáticas: sujeito em (5), objeto direto em (6), complemento relativo em (7) e adjunto adverbial em (8), sendo que as duas últimas normalmente implicam o uso de preposição. Apesar das diferentes funções relativizadas, o padrão esquemático subjacente é o mesmo: REL V (X).

Os diferentes padrões da relativa restritiva finita exibem determinadas características em termos fonológicos e morfossintáticos. No caso de PREP REL V (X), há mais massa fônica devido à presença de elemento gramatical (preposição), o qual marca a dependência sintática entre o nome/verbo regente e o termo regido. Para REL V (X), temos ausência da preposição e, em decorrência, menos massa fônica, e ausência de marcação de dependência sintática para o caso das relativas de funções preposicionadas. Já no padrão $\mathrm{REL}_{\mathrm{i}} \mathrm{PRON}_{\mathrm{i}} \mathrm{V}(\mathrm{X})$, há presença de elemento gramatical (pronome cópia) e, em consequência, mais massa fônica; há marcação de dependência sintática com uso de preposição no caso de relativas de funções preposicionadas.

Os três padrões identificados realizam uma estrutura mais esquemática, a qual representa a construção relativa restritiva finita e pode ser assim configurada: $\left[(\mathrm{PREP})+\mathrm{REL}_{(\mathrm{i})}+\left(\mathrm{PRON}_{\mathrm{i}}\right)+\mathrm{V}(\mathrm{X})\right]$. Dessa forma, podemos pensar, em termos hierárquicos, em um esquema do qual derivam três microestruturas. A Figura 1 ilustra essa hierarquia construcional. 
Figura 1 - Hierarquia construcional da relativa restritiva finita

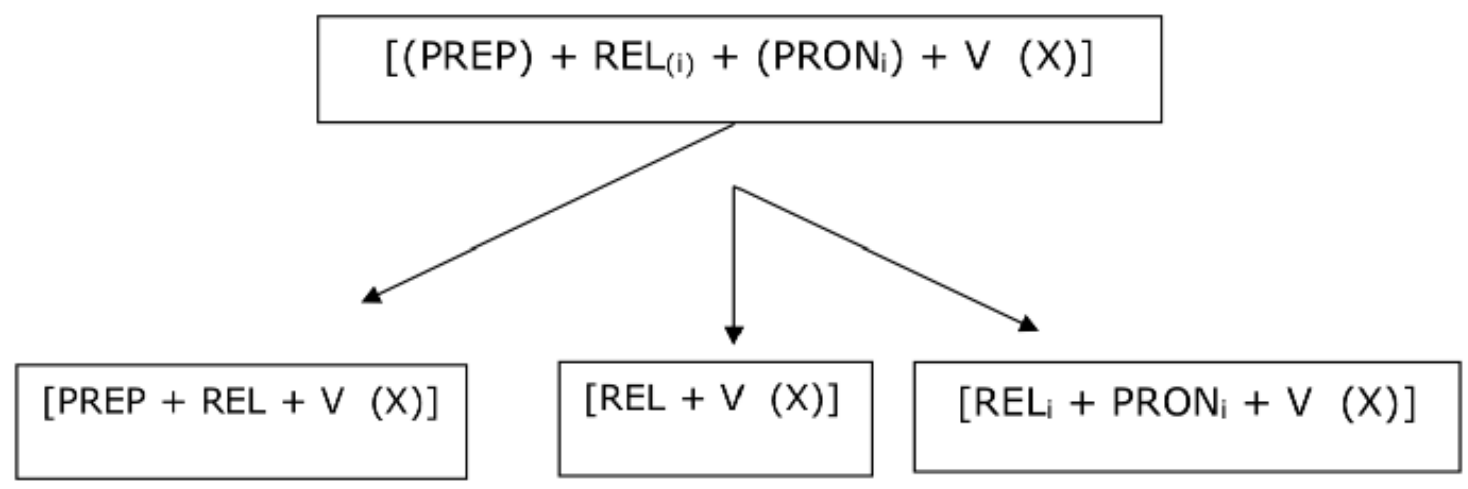

Do ponto de vista da propriedade de esquematicidade, podemos considerar a construção em tela como esquemática, visto que seus slots ${ }^{3}$ estão identificados apenas em termos de categorias que podem preenchêlos, a saber, preposição, pronome, verbo, ao mesmo tempo em que existe um elemento mais aberto, no caso, o X, que pode ser preenchido por uma variedade maior de elementos. Com relação à produtividade, podemos considerá-la como relativamente produtiva, dado que licencia três padrões estruturais ou microconstruções, construções-tipo conforme Traugott e Trousdale (2013). Trata-se de estruturas subespecificadas, com um grau menor de esquematicidade, que podem ter, em alguma medida, preenchimento ou maior especificação de preenchimento de seus slots, como é o caso da presença obrigatória de preposição na primeira micro e de pronome cópia na terceira microconstrução.

\section{Aspectos funcionais da construção relativa restritiva finita}

Tomar a relativa restritiva finita como uma construção implica também identificar propriedades funcionais a ela associadas. De modo geral, a essa construção corresponde a função semântica de delimitar/ recortar o referente de um nome antecedente. Pragmaticamente, suas instâncias de uso se relacionam ao propósito de o falante esclarecer a seu interlocutor o referente específico a que remete, evitando, por exemplo, que este selecione um elemento diferente daquele em questão. Consideremos a amostra (9).

(9) Vendo que eu ia me dar mal eu comecei a andar de volta para o outro lado do túnel e fui com meu primo ligar para casa em um orelhão que tem entre os túneis. ( $\& \& G$ Rio de Janeiro, língua escrita)

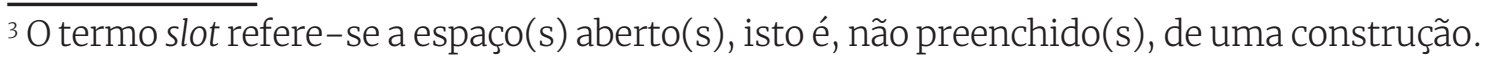


v. 8 (esp.)

$28-44$ set. 2018

Nesse trecho, o informante fala sobre uma situação de perigo por que passou e de como procurou sair-se dela. Nesse relato, faz referência a um telefone público (orelhão) do qual ligou para o primo. Para situar o interlocutor de onde exatamente havia ligado, fez uso de uma oração relativa para recortar semanticamente o referente de um orelhão, de modo a indicar que não se trata de um qualquer, mas, precisamente, daquele que há (havia) entre os túneis.

Os três padrões microconstrucionais da relativa restritiva também exibem propriedades funcionais particulares. Os usos desses padrões estão relacionados a questões de ordem cognitiva e interacional. Conforme algumas pesquisas sobre as estratégias de relativização têm constatado (BISPO, 2009; 2014a,b; CAMACHO, 2012), ocorrências como (10), uma instanciação da microconstrução PREP REL V (X), demandam maior custo cognitivo, envolvendo menos transparência na relação entre termo regente e termo regido.

(10) O lugar da minha casa em que gosto de ficar é a sala. Há dois ambientes, num fica a mesa de jantar, o aparelho de som e um carrinho de chá, que serve de bar. (D\&G Rio de Janeiro, língua escrita)

O uso de preposição antes do pronome relativo implica a realização, por parte do falante/escrevente, de operações sintáticas internas à oração relativa, no sentido de reconhecer que essa preposição é requerida por um elemento verbal ou nominal dela distanciado, qual é a preposição a ser empregada e que posição ela ocupará na cláusula. Na amostra apresentada, o redator, tendo conhecimento da moldura semântica do verbo ficar, da qual a preposição em faz parte, ativa seu conhecimento previamente armazenado (BYBEE, 2010) sobre (i) a moldura sintático-semântica de ficar na acepção com que foi empregado, o que inclui seu complemento circunstancial e a preposição que o precede, e (ii) o rearranjo estrutural da oração, o que implica alteração da ordem dos termos, particularmente do complemento (o lugar da minha casa = que) e, por consequência, da preposição que o acompanha. Dada a distância entre verbo e complemento e a anteposição deste, a relação entre ambos torna-se mais opaca.

Já nas instâncias de uso da microconstrução $\mathrm{REL}_{\mathrm{i}} \mathrm{PRON}_{\mathrm{i}} \mathrm{V}(\mathrm{X})$, a relação entre termo regente e termo regido é mais transparente, visto que se mantém a linearidade da oração, com o complemento seguindo o verbo. É o que se pode observar na ocorrência destacada em (11). 
(11) ... então quando o cara chegou simplesmente botou chave em todos os corredores ... todas as portas ... fechou ... depois das sete e quinze ninguém entrava mais ... só saía de dez e quinze ... então nós tínhamos um professor que nós não gostávamos dele ... era um professor de mecanografia e ele era louco ... o professor era simplesmente louco ... (D\&G Natal, língua falada)

Nesse caso, o uso do pronome cópia (ele) após o verbo gostar deixa mais clara para o ouvinte a relação entre esses termos, tanto por meio da repetição do antecedente do pronome relativo quanto pela manutenção da ordem SVComp da oração.

No que diz respeito à microconstrução [REL V (X)], a mais frequente em nossos dados, a recorrência a suas instâncias de uso parece envolver tanto o princípio da economia (ZIPF, 1935 apud HAIMAN, 1985), quanto a generalização de um padrão de formação de oração relativa, via repetição. As instâncias de uso desse padrão apresentam menor complexidade estrutural em relação aos demais, pois estes envolvem preposição e/ou elemento cópia a mais. Decorre daí menor complexidade cognitiva implicada, sobretudo em comparação à microconstrução PREP REL V (X), dadas as operações já referidas anteriormente. Além disso, a alta frequência de relativas de sujeito e objeto direto, provavelmente, fez com que seu padrão estrutural fosse estendido a relativas de outras funções (complemento nominal, complemento relativo, objeto indireto, adjunto adverbial), com a consequente ausência da preposição. Assim, o esquema [REL V (X)] passa a ser mais comumente acessado pelo falante da língua portuguesa como o padrão de oração relativa, sendo tomado como uma única unidade de processamento (BYBEE, 2010). Consideremos os dados em (12), (12a), (13) e (14).

(12) A sala não tem muitos móveis, só uma rede, uma mesinha de metal preta, uma cadeira de couro e madeira, quatro de metal preto que geralmente ficam fechadas e esta cadeira que eu gosto. (D\&G Rio de Janeiro, língua escrita)

(13) ...quatro de metal preto que geralmente ficam fechadas e esta cadeira de que eu gosto.

(14) O trunfo serve para cortar o jogo que está na mesa, mas só pode ser usado quando o jogador não tiver nenhuma carta do naipe que está sendo jogado. (D\&G Rio de Janeiro, língua escrita) 
v. 8 (esp.)

$28-44$

set.

2018

(15) ... como é que eu posso falar? sistema de segurança... é tudo falho... as pessoas... não... não são de confiança... então... quer dizer... eu acho que p/ sabe? a mensagem que os políticos passam... é propriamente essa... entendeu? (D\&G Rio de Janeiro, língua falada)

Comparada à oração destacada em (12a), que ilustra a microconstrução [PREP REL V $(X)$ ], a que destacamos em (12), realização de REL V (X), demanda menor custo cognitivo, menor esforço de produção/processamento. Primeiro porque há um elemento a menos (a preposição) e, segundo, porque o uso desse elemento em (12a) implica o conhecimento da moldura sintático-semântica do verbo gostar, a seleção da preposição a ser utilizada (de, no caso) e o rearranjo estrutural que envolve a anteposição do complemento do verbo e da preposição que o acompanha.

Quanto à questão da generalização, observemos que o padrão microconstrucional que licencia as orações negritadas em (12), (13) e (14) é o mesmo: [REL V (X)]. Em (12), o elemento relativizado assume função preposicionada (complemento relativo), já em (13) e (14), isso não se dá, sendo as relativas de sujeito e objeto direto, funções mais frequentemente relativizadas conforme Keenan e Comrie (1977). Ou seja, um esquema mais recorrente (o padrão de relativas de sujeito e objeto direto) se rotiniza pelo uso e passa a servir de exemplar (BYBEE, 2010) para as relativas de outras funções gramaticais (no caso, as preposicionadas).

Em termos interacionais, as microconstruções da relativa restritiva finita também apresentam especificidades. Os dados de nossa amostra, particularmente do corpus $D \& G$, e os resultados de pesquisas sobre as estratégias de relativização indicam que o uso de orações sancionadas pela micro [PREP REL V (X)] está relacionado a situações de maior monitoramento no uso da língua, ao passo que as orações licenciadas pelas microconstruções [REL V (X)] e $\left[R_{E L} L_{i} P_{R O N} V(X)\right]$ vinculam-se a situações de menor formalidade, embora não se limitem a elas.

Conforme mostram os quantitativos da tabela 2, houve apenas duas ocorrências de PREP REL V (X) na fala (1,8\%) enquanto, na escrita, o percentual atingiu 24\%. Bispo (2009), investigando as estratégias de relativização no $\mathrm{PB}$, com foco nas chamadas cortadoras, verificou que essa estratégia, que realiza, como vimos, o padrão REL V (X), responde 
por $90 \%$ nos dados de fala para os casos de relativas de funções preposicionadas (complemento relativo, objeto indireto, complemento nominal, adjunto adverbial); na escrita, o autor verificou 53\% de ocorrências com as relativas encabeçadas pela preposição. Ou seja, as instâncias de uso dessas microconstruções estão ligadas a situações de maior ou menor monitoramento no uso da língua.

Fatores relativos à natureza do gênero textual, aos propósitos comunicativos pretendidos, à esfera de circulação, à proximidade/ distância social entre interlocutores, entre outros, também condicionam a escolha do tipo de relativa a ser utilizada. Consideremos, para fins de análise, as amostras em (15), uma propaganda da Caixa Econômica Federal, e (16), trecho de um artigo publicado na revista Carta Capital.

(16) A Caixa tem o crédito que você precisa. (Istoé, 26 nov. 2008)

(17) Em 1998, a expectativa de vida americana foi superada pela média dos países da OCDE. Hoje, ela é um ano e meio mais baixa: 78,7 ante 80,3 anos. Em 2013, pesquisadores do Institute of Medicine procuraram entender as razões pelas quais o país levava desvantagem crescente. ( $O$ "American way of live" faz bem à saúde? Carta Capital. Disponível em: https://www.cartacapital.com.br/. Acesso: 26 fev. 2018)

O uso de uma instância de [REL V (X)] para codificar uma relativa de função preposicionada (complemento relativo, no caso), além de motivada por pressões cognitivas em termos de economia de esforço, pode também ser explicada pela natureza do gênero textual e pelos propósitos comunicativos implicados: dado que a amostra constitui uma propaganda, objetiva atingir um público cada vez maior a fim de obter a adesão do interlocutor ao serviço oferecido (linha de crédito), sendo a oração em destaque mais expressiva que sua contraparte formal escrita (A caixa tem o crédito de que você precisa), ou seja, seu uso representa um ganho comunicativo. Já a relativa em (16), que ilustra a micro [PREP REL $\mathrm{V}(\mathrm{X})$ ], tem seu emprego favorecido também por questões interacionais: a oração figura em artigo publicado em uma revista de circulação nacional, o qual trata de assunto de relevância social, no caso, a expectativa de vida americana, e, naturalmente, o veículo de comunicação espera contar com a credibilidade de seus leitores em relação ao que publica. Essas questões resultam no uso mais monitorado da língua, o que implica a seleção de estruturas que atendam a convenções da escrita formal. 
v. 8 (esp.) $28-44$ set. 2018

Por fim, resta dizer que é também por questões pragmáticas que a oração licenciada pela microconstrução $\left[R L_{i} P R O N_{i} V(X)\right]$ é bem menos utilizada: trata-se de uma forma sujeita à avaliação social negativa por parte dos falantes, daí ser evitada.

\section{Considerações finais}

Com base nos pressupostos da LFCU conjugados a contribuições da GC, abordei a oração relativa restritiva finita como uma construção, nos termos de Goldberg (1995, 2006), Croft (2001) e Traugott e Trousdale (2013). Analisei instâncias de uso desse tipo oracional, com vistas a identificar padrões estruturais que as licenciam, a organizar esses padrões em rede e a explicitar aspectos cognitivos e interacionais implicados em tais instâncias de uso.

O levantamento de dados a que procedi permitiu identificar três padrões microconstrucionais, a saber, REL V (X), PREP REL V (X) e REL $\mathrm{PRON}_{\mathrm{i}} \mathrm{V}(\mathrm{X})$. Tais padrões estão ligados diretamente a uma estrutura esquemática maior que os sanciona, a construção relativa restritiva finita, a qual pode ser representada por [(PREP) $\operatorname{REL}_{(\mathrm{i})}\left(\mathrm{PRON}_{(\mathrm{i}))} \mathrm{V}(\mathrm{X})\right]$. Trata-se de uma construção esquemática, com slots identificados apenas em termos de categorias gramaticais, e relativamente produtiva, visto que licencia três microestruturas.

A análise dos dados permitiu considerar que o padrão REL V (X), que licencia as relativas de sujeito e objeto direto, generaliza-se e é estendido para as relativas de funções preposicionadas (complemento nominal, complemento relativo, objeto indireto, adjunto adverbial) via rotinização pela frequência de uso. Esse padrão passa a ser tomado como exemplar de estruturação da oração relativa, sendo acessado como uma única unidade de processamento (BYBEE, 2010).

Em termos de fatores cognitivos e interacionais relacionados às instâncias de uso das três microconstruções, foi possível verificar que a cada padrão microconstrucional correspondem determinados aspectos. Assim, pressões por menor esforço de codificação e de processamento e por maior rapidez comunicativa associam-se às ocorrências de REL V (X); já as instanciações de PREP REL V (X) vinculam-se ao atendimento de demandas comunicativas decorrentes de situações de uso mais monitorado da língua; por fim, os construtos da micro [REL $\mathrm{R}_{\mathrm{i}} \mathrm{PRN}_{\mathrm{i}} \mathrm{V}(\mathrm{X})$ ], por questões interacionais, são restritos a contextos de mais informalidade e comumente evitados na interação verbal em virtude de rejeição social. 


\section{Referências}

AMORIM, M. B. Orações adjetivas não prototípicas do português: relações discursivas e gramaticais. Tese (Doutorado em Estudos de Linguagem). Niterói: Universidade Federal Fluminense, 2011.

BARLOW, M.; KEMMER, S. (Eds.). Usage based models of language. Stanford, Cambridge: CSLI, 2000.

BISPO, E. B. Oração adjetiva cortadora: análise de ocorrências e implicações para o ensino de português. Linguagem \& Ensino, v. 10, n. 1, p. 163-186, 2007.

$\mathrm{BISPO}$, E. B.. Estratégias de relativização no português brasileiro e implicações para o ensino: o caso das cortadoras. Tese (Doutorado em Estudos da Linguagem). Natal: Universidade Federal do Rio Grande do Norte, 2009.

BISPO, E. B.. Estratégias de relativização no PB: motivações discursivointeracionais e cognitivas. In: BISPO, E. B.; OLIVEIRA, M. R. de. Orações relativas no português brasileiro: diferentes perspectivas. Niterói: EdUFF, p. 131-155, 2014a.

BISPO, E. B.. Orações relativas em perspectiva histórica: interface uso e cognição. Veredas, v. 18, n. 1, p. 222-235, 2014 b.

BRITO, A. M. M. A sintaxe das orações relativas em português. Tese (Doutorado em Linguística Portuguesa). Universidade do Porto, Portugal, 1988.

BYBEE, J. Language, usage, and cognition. Cambridge, UK: CUP, 2010.

CAMACHO, R. G. Transparência e opacidade na seleção de estratégias de relativização no português. Linguística, n. 27, p. 47-76, 2012.

CÂMARA, A. L. A oração relativa em português: interface entre a descrição e o ensino. Tese (Doutorado em Estudos Linguísticos). São José do Rio Preto: Universidade Estadual Paulista Júlio de Mesquita Filho, 2015.

CORREA, V. R. Oração relativa: o que se fala e o que se aprende no português do Brasil. Tese (Doutorado em Linguística). Campinas: Universidade Estadual de Campinas, 1998.

CROFT, W. Radical Construction grammar: syntactic theory in typological perspective. Oxford: Oxford University Press, 2001.

DECAT, M. B. N. Estruturas desgarradas em língua portuguesa. Campinas: Pontes, 2011.

FURTADO DA CUNHA, M. A.; BISPO, E. B. Pressupostos teórico-metodológicos e categorias analíticas da Linguística Funcional Centrada no Uso. Revista do Gelne. V. 15, n. 1/2, p. 49-74, 2013.

FURTADO DA CUNHA, M. A.; BISPO, E. B.; SILVA, J. R. Linguística Funcional Centrada no Uso: conceitos básicos e categorias analíticas. In: CEZÁRIO, $M$. M.; FURTADO DA CUNHA, M. A. (orgs.). Linguística Funcional Centrada no Uso: uma homenagem a Mario Martelotta. Rio de Janeiro/Cataguases-MG: FAPERJ/Mauad, 2013, p. 13-36. 
v. 8 (esp.)

$28-44$

set.

2018

GOLDBERG, A. E. Constructions: a construction grammar approach to argument structure. California: Unversitiy of California, 1995.

GOLDBERG, A. E.. Constructions at work: the nature of generalization in language. Oxford University Press, Oxford, 2006.

HAIMAN, J. (Ed.). Iconicity in syntax. Amsterdam: John Benjamins, 1985.

KEENAN, E. L.; COMRIE, B. Noun phrase accessibility and universal grammar. Linguistic Inquiry, n. 8, p. 63-99, 1977.

KENEDY, E. A antinaturalidde de pied-piping em orações relativas. Rio de Janeiro, Tese (Doutorado em Linguística). Rio de Janeiro: Universidade Federal do Rio de Janeiro, 2007.

LEITÃO, R. J. Relativas explicativas: aspectos sintático-semânticos e textualdiscursivos. Tese (Doutorado em Linguística). Fortaleza: Universidade Federal do Ceará, 2009.

MARTELOTTA, M. E. Mudança linguística: uma abordagem baseada no uso. São Paulo: Cortez, 2011.

MARCHESAN, A. C. As Relativas Livres no Português Brasileiro. Florianópolis, Tese (Doutorado em Linguística). Florianópolis: Universidade Federal de Santa Catarina, 2012.

MOLLICA, M. C. de M. o estudo da cópia nas construções relativas do português. Dissertação (Mestrado em Letras). Rio de Janeiro: Pontifícia Universidade Católica, 1977.

PINHEIRO, C. L. A relativização no português oral culto de Fortaleza. Dissertação (Mestrado em Linguística). Fortaleza: Universidade Federal do Ceará, 1998.

SILVA, B. G. S. G. da. As estratégias de relativização na escrita de portugueses dos séculos XVI, XVII e XVIII. Tese (Doutorado em Linguística). Rio de Janeiro: Universidade Federal do Rio de Janeiro, 2011.

SOUZA, E. S. de A. C. de. A interpretação das cláusulas relativas no português do Brasil: um estudo funcional. Tese (Doutorado em Linguística). Rio de Janeiro: Universidade Federal do Rio de Janeiro, 2009.

TARALLO, F. Relativization Strategies in Brazilian Portuguese. University of Pennsylvania, Ph. D. dissertation, 1983.

TOMASELLO, M. (ed.). The new psychology of language. New Jersey: Lawrence Erlbaum, 1998.

TRAUGOTT, E. C.; TROUSDALE, G. Constructionalization and constructional changes. Oxford: Oxford University Press, 2013.

VAREJÃO, F. de O. A. Variação das estratégias de concordância verbal e em estratégias de relativização no português europeu popular. Tese (Doutorado em Linguística). Rio de Janeiro: Universidade Federal do Rio de Janeiro, 2006.

VOTRE, S. J.; OLIVEIRA, M. R. de. Corpus Discurso \& Gramática - a língua falada e escrita na cidade do Rio de Janeiro. UFRJ, 1995. Impresso. 